District Committees of the Engineering and Allied Employers National Federation, the Amalgamated Engineering Union, the major engineering institutions and the Regional Advisory Council for Technical and other Forms of Further Education, that a National Apprentice Council and associated regional councils should be established, and that their directing activities should be supported by a national fund provided jointly by the State, the local education authorities, and the employers and trade unions concerned.

After referring to the serious shortage of science and technical teachers, Sir Willis says that the more effectively industry fulfils its responsibilities in the fields of education and training the fuller will be the benefit which will accrue to it-employer and employee alike-and through it to the nation.

\section{DIGESTION IN THE RUMINANT}

$I^{\mathrm{N}}$

$\mathrm{N}$ his presidential address to Section M (Agriculture) Dr. D. P. Cuthbertson points out that the outstanding difference between the ruminant and other herbivores is that the former pre-ferment their food through microbial action in the first two compartments of the complex stomach - the reticulo-rumen sac-before digestion by enzymes secreted by the digestive glands begins in the abomasum or fourth stomach. Considerable absorption of the soluble products of microbial activity takes place from this sac. In the third compartment, the omasum, absorption of water is the main feature.

The reticulo-rumen sac thus forms a fermentation vat in which bacteria and protozoa are established under highly reducing conditions when the animal is quite young. Fermentation of cellulose through microbial activity takes place there; otherwise it would be unavailable through lack of a cellulase in the digestive glands. In grass itself, and especially in root crops, other fermentable carbohydrates exceed cellulose in amount and being more soluble and less resistant structurally and mechanically than cellulose, are more readily fermentable by a much wider variety of micro-organisms, but not necessarily to the same ratio of desired products.

The reticulo-rumen sac is never empty, and constitutes a functional field in which all the activities are organized for utilization of microbial products and all factors therein make for a steady state. The activity of the salivary glands, the process of rumination involving re-mastication, the absorption of the products of microbial activity and the interchange of ions between rumen contents and blood-in the case of sodium against the concentration gradient-all contribute to the continuity of microbial action during the whole life of the animal, and produce conditions which one can scarcely hope to reproduce in vitro. Nevertheless, by observation of the microorganisms-the bacteria and the protozoa-at the site of their attack on food particles, and in isolation in culture, and by a study of the soluble products of fermentation and their absorption, much information about this microcosm has been obtained.

Consideration is also given by Dr. Cuthbertson to the early development of the ruminant : to the role of the saliva, and to the passage of food through the alimentary tract.

In the rumen, dietary protein is subjected to fairly vigorous hydrolytic conditions, and the low-molecular products, including amino-acids, are then assimilated by micro-organisms and incorporated into their body protein or, if amino-acids accumulate in excessive amounts, the micro-organisms acquire the power to ferment them deaminatively to ammonia, short-chain fatty acids and carbon dioxide. Further, it is known that urea and ammonia can also be utilized by the micro-organisms for elaboration of their own body proteins. These proteins are of good biological value and are presumed to be digested in the abomasum and small intestine in similar fashion to that taking place in the non-ruminant.

When cellulose and starch are broken down by the micro-organisms to soluble sugars, these, like other soluble sugars in the diet, are fermented to give shortchain fatty acids. These acids, together with those derived from protein, are absorbed from the rumen into the blood stream. It has been calculated that for hay-fed sheep, about 70 per cent of the total energy requirements is provided by these fatty acids. These short-chain acids are quantitatively much more important than glucose as a source of energy.

While the microbiological synthesis of fat-soluble vitamins (other than vitamin $K$ ) has not yet been unequivocally demonstrated, the metabolic needs for the various B vitamins are met by synthesis in the reticulo-rumen through microbial activity. The synthesis of vitamin $\mathrm{B}_{12}$ is conditioned by the cobalt content of the feed. Ascorbic acid appears to be synthesized in the ruminant's own tissues.

This pre-gastric microbial digestion confers important benefits upon the ruminant. Energy from fibrous foods, which could not otherwise be obtained, is more efficiently garnered and the available energy is yielded over a longer period of time, so that the animal is more resistant to periods of starvation ; the uptake of nitrogen is controlled and that from non-protein sources utilized more efficiently via microbial proteins; and considerable synthesis of vitamins takes place. This aspect of the physiology is as fascinating to the investigator as it is important for the husbandman. Further advances should help to clear our understanding of some of the so-called 'metabolic' diseases.

\section{THE CULTURAL VALUE OF LOCAL SOCIETIES}

T ORD BOYD-ORR, in his presidential address to - Section X (Assembly of Corresponding Societies), remarks that though all governments are clamouring for more science, human society is suffering acute indigestion from an overdose of science. For example, it is estimated that in a third world war with the weapons we already have, 90 per cent of the people in the northern hemisphere would be wiped out. One would have thought that that was plenty to be going on with, yet in government 'hush-hush' laboratories there is probably more research to improve weapons of war than in any other field.

In industry, science has increased the output per man and the total capacity for production to such an extent that although a large part of industrial potential is engaged in producing armaments, factories produce goods for peaceful uses faster than they can be dispersed and consumed, so that production has to be slowed down with resulting unemployment which, in the United States where tech- 